\title{
Influence of the different composites (PLA/PLLA/HA/ $\beta$-TCP) contents manufactured with the use of additive laser technology on the biocompatibility
}

\author{
ANNA E. WOŹNA ${ }^{1 *}$, ADAM JUNKA ${ }^{2}$, VIKTORIA W. HOPPE ${ }^{1}$ \\ ${ }^{1}$ Department of Laser Technology, Automation, and Production Organization, \\ Wrocław University of Science and Technology, Wrocław, Poland. \\ ${ }^{2}$ Departament of Pharmaceutical Microbiology and Parasitology, Wroclaw Medical University, Wrocław, Poland.
}

\begin{abstract}
Purpose: In recent years, it has become extremely important to search for more and more natural and biocompatible materials that allow for the reconstruction of natural tissues with as few side effects as possible. The aim of the present paper is to define mechanical properties such as compressive stress and Young's Modulus and to estimate the ability of human bone cell strains to form biofilm on bioresorbable composites manufactured of polylactide and poly-l-lactide (PLA and PLLA) and hydroxyapatite and tricalcium phosphate (HA and $\beta$-TCP) with the use of Selective Laser Sintering (SLS) method. Methods: Microbiological tests were conducted on three variants of solid specimen made with additive laser technology. Samples with different chemical compositions were made with appropriate manufacturing parameters ensuring stability of both composite ingredients. Microbiological in vitro tests helped to determine cytotoxicity of specific samples toward bone cells. Results: The results obtained indicate significantly increased ability of osteoblasts to form colonies on the surface of materials with higher content of hydroxyapatite ceramics compared to surfaces of lower hydroxyapatite content. Conclusions: The data provided can be useful for future applications of the SLS technology in production of bioresorbable PLA/PLLA/HA/ $\beta$-TCP medical implants.
\end{abstract}

Key words: biomaterials, additive manufacturing, biopolymers, bioceramic, biocompatibility, osteoblasts

\section{Introduction}

Materials used in the bone replacement surgery are specific type of biomaterials. There is a number of requirements to meet, starting from the biocompatibility, through ease of processing, to specific strength properties, infrequently dependent on the patient personal parameters [2]. In the case of significant bone loss, the organism is unable to regenerate by its own. Therefore, the loss needs to be replaced with an appropriate implant. Modern implants should display high level of biocompatibility and low cytotoxicity [16]. However, taking the flourishing of this field and the solutions appearing in an increasing number into account, there is still no ideal invention that fully meets the needs of every patient affected by the problem.
Therefore, additive technologies are still with huge potential, making it possible not only to produce an implant adapted to the patient's bone loss geometry, but also to the properties of the certain bone, allowing for the adjustment of loads around the implant. Osteoblasts are bone-forming cells [26] which play crucial role in the success of the implantation. There are number of clinical complications with osseointegration which are needed to stabilize bone replacement in situ. That is the main condition of protection implant surrounding tissues and successful treatment [5], [26]. The easiest way to ensure the high possibility of osseointegration is to apply materials of the high biocompatibility level which naturally stimulates tissues to regeneration. Materials chosen to the study are well-known for their excellent biocompatibility with human tissues [11], [18]. Polylactide is a polymer from

\footnotetext{
* Corresponding author: Anna E. Woźna, Department of Laser Technology, Automation, and Production Organization, Wrocław University of Science and Technology, Wrocław, Poland. Phone: 0048503655331, e-mail: anna.wozna@pwr.edu.pl

Received: January 14th, 2021

Accepted for publication: April 30th, 2021
} 
the group of aliphatic polyesters, it is fully biodegradable, as it is obtained from renewable raw materials of plant origin, such as corn or potato starch, sucrose from sugar beet or sugar cane, lactose from whey or waste biomass. PLA is a thermoplastic polymer similar to polystyrene, however, it has a much higher melting point - even up to $180{ }^{\circ} \mathrm{C}$. Polylactide is a partially crystalline polymer (degree of crystallization up to $60 \%$ ) with a glass transition temperature between 50 and $80{ }^{\circ} \mathrm{C}$. Depending on the method of production, it is possible to obtain different types of polylactide, such as PLA, PLLA and PDLA. PLLA is formed by the polymerization of L-lactide and has a crystallization degree of approximately $37 \%$, a glass transition temperature of $60-65{ }^{\circ} \mathrm{C}$, a melting point in the range of $170-180^{\circ} \mathrm{C}$. In the case of PDLA, we are dealing with an amorphous structure. Degree of crystallization has an impact on the resorption time - the more crystalline the structure is, the more time is needed for the degradation [8]. Two kinds of polylactide (PLA and PLLA) were chosen for the study because of their excellent biomedical potential. Additionally, both of the materials have structure with crystalline degree, so it is more reliable to compare those materials and how dopants can affect the properties. As the properties of the materials are determined in reference to the potential use, the processing methods are still leaving field to research because additive manufacturing methods are still not commonly used to produce composites or ready to use bone replacements. The properties after processing should be well known, and that will ensure stable process of manufacturing in the future.

Method of manufacturing the bioresorbable composites in the study is based on SLS technology, which belongs to the group of Laser Power Bed Fusion (L-PBF). In this method, the powder is the material used to form the finished elements, layer by layer, using a laser beam. This technology is ideal for the use with materials with low melting points, e.g., polymers. However, the study [13] points out that surface modification of PLLA, semicrystalline and amorphous, has a negative effect on the mechanical properties of polymers. Samples in the mentioned study were not printed out, but after fabrication with hydraulic press, surface was modified with $\mathrm{CO}_{2}$ laser beam. The obtained results raise the question of whether admixtures of high-melting materials are able to positively affect the properties of temperature-processed polymers.

One of such admixtures, interesting in terms of bone regeneration, is hydroxyapatite (HA) with its variety. Hydroxyapatite, or calcium hydroxyphosphate, is calcium phosphate. In the body, it is a mineral scaffold for connective tissue, responsible for the me- chanical strength of bones. Hydroxyapatite bioceramics are highly biocompatible for both soft and hard tissues. Moreover, unlike many materials, it is not carcinogenic, cytotoxic, irritating or allergenic. It adapts very well to a living organism and does not cause an inflammation. It exhibits physical and chemical stability for a very long time. Besides, it tolerates sterilization very well. Studies have shown that crystalline HA is the thermodynamically most stable calcium phosphate at $\mathrm{pH}$, temperature and physiological fluid composition [4]. Whitlockite ceramics (calcium triphosphate - TCP) is characterized by high biocompatibility and bioactivity. This material shows even higher degree of resorption than HA. The rate of degradation due to hydrolysis decreases as the $\mathrm{Ca} / \mathrm{P}$ ratio is lowered. $\beta$-TCP with a $\mathrm{Ca} / \mathrm{P}$ ratio value of 1.5 resorbs 3-12 times faster than $\mathrm{HAp}$ with a $\mathrm{Ca} / \mathrm{P}$ ratio of 1.67 [4], [7], [16].

Studies have shown that ceramics based on calcium phosphates can participate in the remodeling process, because osteoclasts have the ability to resorb them similarly to the natural bone degradation mechanism [27]. The outgrowth of $\mathrm{CaP}$ scaffolds with natural bone is a key process in the regeneration of bone defects and depends on many factors, especially the resorption rate. The surface of the CaP-ceramics is dissolved by the acidic micro-environment and the resorbed crystals are consequently degraded by the osteoclasts [27].

The aim of the following paper is to evaluate the ability of human bone cells to form colony on PLA/HA composites made with L-PBF laser technology, of various chemical composition within individual samples and determination of chosen mechanical properties of the before mentioned composites after treatment with the high temperature source.

\section{Materials and methods}

\subsection{Material preparation}

Materials processed by layers with a laser must meet a number of requirements regarding: form, particle shape, particle size. These features are important due to the need of applying a layer of controlled thickness to the powder bed. Materials for layered processing should be available in the form of powders with a particle size in the range of $40-100 \mu \mathrm{m}$ - thus, layers with thicknesses in the same range can be obtained.

The shape of the particles is a very important factor for several reasons [1], [3], [19]: 
- The material is gravitationally distributed on the working platform by means of a movable feeder - the shape of the particles determines the degree of success in spreading a single layer,

- Spherical particles move more freely on the platform than particles with a different shape,

- A layer that is as uniform as possible is only possible if a spherical powder with the most homogeneous particle size distribution is used.

Therefore, it was necessary to adapt the original form of the material to the method used. Hydroxyapatite ceramics can be purchased in the form of spherical powder with the required particle size. Ceramics used in the study were delivered by Tomita Pharmaceutical Co. Molecular. The weight of HA was approximately $1004.6 \mathrm{~g} / \mathrm{mol}$. $\beta$-TCP powder was delivered by Sigma Aldrich, the molecular mass was about $310.18 \mathrm{~g} / \mathrm{mol}$. Bioresorbable polymer (Ingeo 3001D, Nature Works LLC, the USA) was purchased in the form of injection moulding granules with a grain size in the range of 2$4 \mathrm{~mm}$ (Fig. 1a). Material characteristic are: average molecular weight of about $155.000 \mathrm{~g} / \mathrm{mol}$, glass-transition temperature of about $73{ }^{\circ} \mathrm{C}$ and melting point of $170{ }^{\circ} \mathrm{C}$. Poly-l-lactide for medical use was purchased in particulate form, but not spherical, and the particle size was about $1 \mathrm{~mm}$, delivered by Sigma Aldrich (Fig. 1a) with molecular weight of $101.000 \mathrm{~g} / \mathrm{mol}$, glass-transition temperature of about $65^{\circ} \mathrm{C}$ and melting point at $170{ }^{\circ} \mathrm{C}$. The level of crystallinity of PLA was about $60 \%$ and PLLA was about $40 \%$. D-lactide content in PLA was $\sim 1.5 \%$.

Three independent schemes of material preparation were considered in two types of the methods: mechanical grinding and chemical methods of shredding. For mechanical grinding, cryogenic mill was used. Mechanical tests with the use of a cryogenic mill did not bring satisfactory results.

Due to their characteristics, polymeric materials, unlike metallic materials, can be processed using a number of chemical methods. Based on the literature data, the most optimal chemical methods have been selected to obtain the material of the desired particle size and shape [12], [14], [17]. Selected methods were solidin-oil-in-water emulsion solvent evaporation method: precipitation upon dissolution in chloroform, freeze-drying, precipitation upon dissolution in dichloromethane.

First, $2-3 \mathrm{~g}$ of PLA were dissolved in $200 \mathrm{ml}$ of methylene chloride. HA powder (7-8 g) was added to the polymer solution which was kept under magnetic stirring for $15 \mathrm{~min}$. The composite solution thus formed was dripped with a dropping funnel into $600 \mathrm{ml}$ of a $0.5 \%$ polyvinyl alcohol (PVA) solution. The magnetic stirrer was then set to $300 \mathrm{rpm}$. After the instillation was completed, the speed was increased to $600 \mathrm{rpm}$. The process thus set was left for $2 \mathrm{~h}$ in order to allow the solvent to evaporate and harden the particles. Finally, the microspheres were vacuum isolated, washed, dried and sieved to remove residual PVA [17].

Satisfactory results were obtained with the shape of spherical particles of the PLA/HA composite with an average particle size of $45 \mu \mathrm{m}$, however, the material did not have the desired flowability, which had a direct impact on the ease of spreading a single layer of powder and its quality. This method made it possible to obtain the material, so far, closest to the assumed requirements. However, based on many trials and problems encountered, it was modified by optimizing the amount of reagents used, as well as increasing the amount of polylactide processed in one go. Moreover, the addition of hydroxyapatite ceramics in the processing stage of the polymeric material was dispensed. The modification of the procedure was obtained by the production of pure polymer powder by the oil-in-water emulsion solvent evaporation method. Course of the procedure: $10 \mathrm{~g}$ of PLA was dissolved in $250 \mathrm{ml}$ of methylene chloride. The resulting polymer solution was dripped with a dropping funnel into $750 \mathrm{ml}$ of a $0.5 \%$ solution of PVA. The magnetic stirrer was set to the highest possible speed and the process was left for at least $12 \mathrm{~h}$ to allow the solvent to evaporate and harden the particles. The (a)

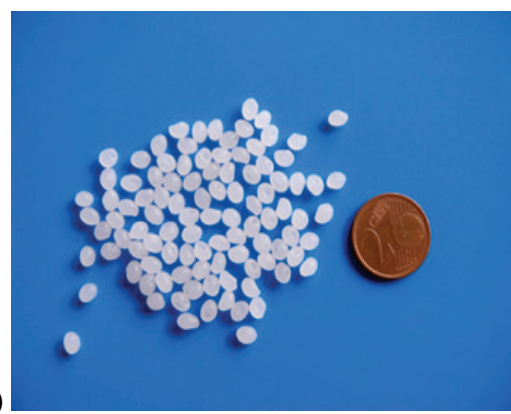

(b)

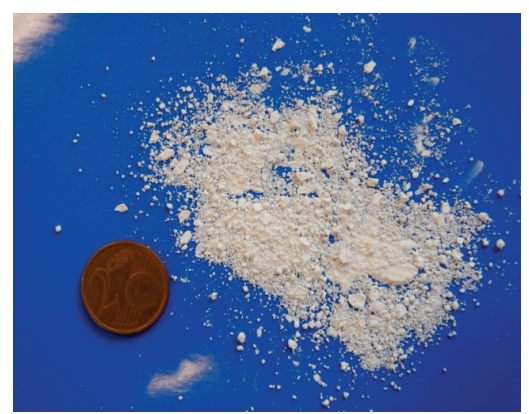

Fig. 1. (a) PLA as delivered, (b) HA as delivered 
microspheres were then vacuum isolated, washed and dried to remove residual PVA.

The modification of the method allowed for:

- the increase the efficiency of the process - at a time, obtained about $10 \mathrm{~g}$ of pure polymer in the desired form, ready to be doped with ceramics,

- the elimination of the problem of clogging funnels with sinter (previously ceramic particles impeded vacuum filtration),

- the elimination of the problem of the solvent remaining in the solution (thanks to the significant extension of the evaporation time, the entire batch of the solvent is removed from the solution, thus obtaining compact particles),

- obtaining a pure polymer powder that can be doped with ceramics (or other materials) in any concentration.

As a result of tests using the method described above, it was possible to obtain the desired form of polymer powder. The pictures below show the processed polymer (Fig. 2) and the mixture constituting an intermediate of the polymer-hydroxyapatite composite (Fig. 3) using the modified method.
A mixture of material obtained by method 3.1 - PLA with admixture of HA.

The obtained powder was mixed with the purchased hydroxyapatite ceramic powder, thanks to which a mixture was obtained which was the input material for processing by the Laser Power Bed Fusion (L-PBF) method.

\subsection{Fabrication L-PBF of PLA/HA composites}

For the fabrication of the composites, the prototype device was used. Ready-made elements were used for the construction of the prototype device: a $\mathrm{CO}_{2}$ laser with a power of $25 \mathrm{~W}$, a precise micrometric table Thorlabs L490M/Z with a range of motion in the $z$ axis of $50 \mathrm{~mm}$, a resolution of $20 \mathrm{~nm}$ and positioning repeatability of $5 \mu \mathrm{m}$, a SCANLAB Intellicube 10 scanning head, a laser and aluminum attenuator piston. A prototype chamber was built using a lifting table and an aluminum piston with a cylinder. A mounting system was designed, consisting of: lower interface, up-
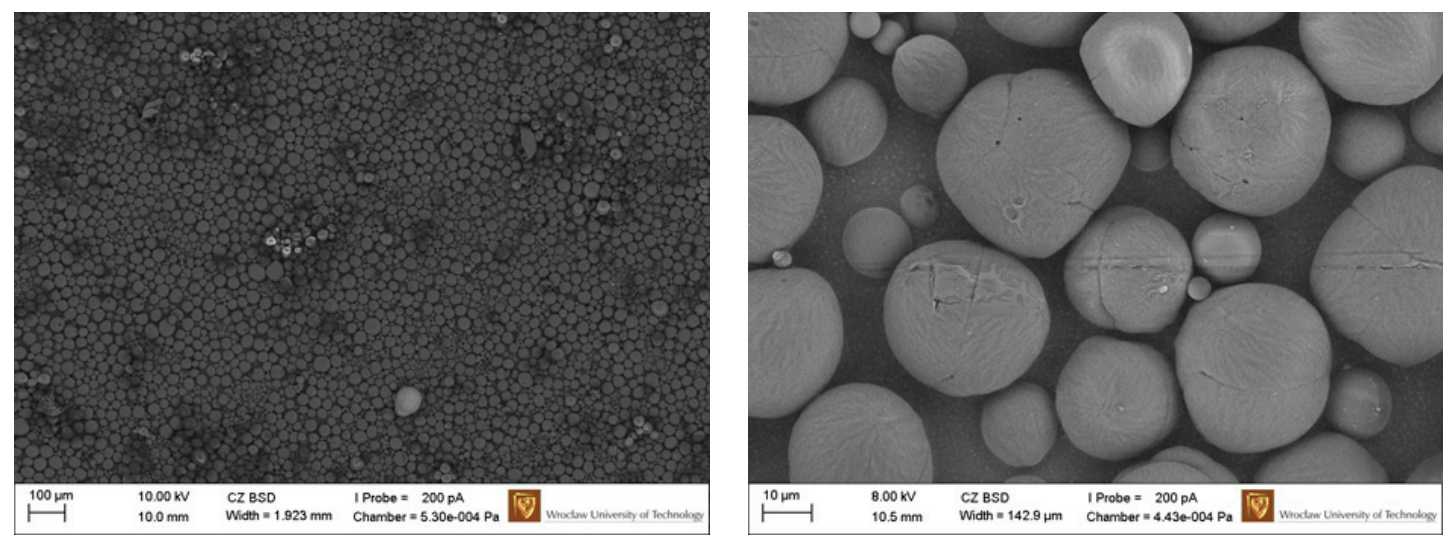

Fig. 2. Polymer after processing
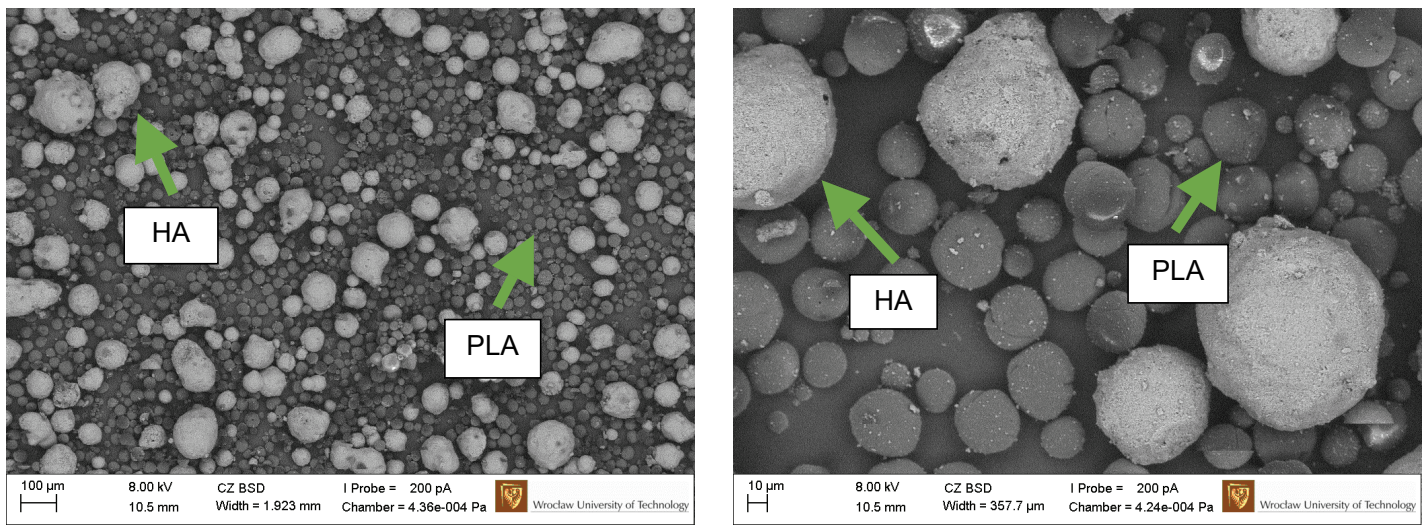

Fig. 3. Mixture of spherical PLA and HA 
per interface, pins, knurled screws and a mounting. Next, the aluminum piston with the cylinder was adapted for assembly with the previously mentioned parts. The whole is connected with $20 \mathrm{~mm}$ aluminum profiles. No additional heating devices were attached, the bed was not heated, as well as the chamber. The described device is shown in the Fig. 4.

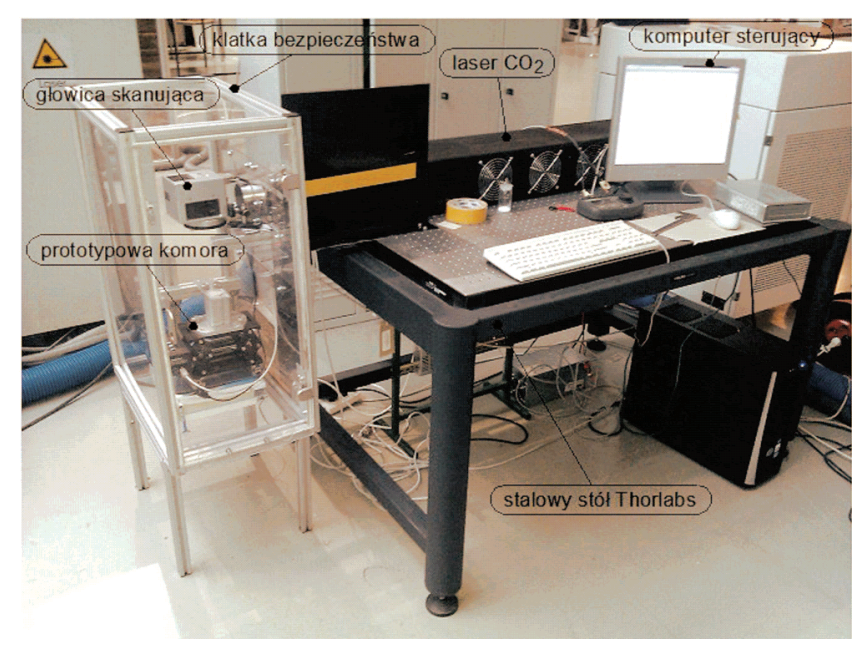

Fig. 4. The prototype device used in the study

Three variants of solid specimen were prepared with additive laser technology. The difference was content of HA and $\beta$-TCP as well as the type of polymer matrix in the bioresorbable composites. Samples with $20 \% \mathrm{HA}$ and $30 \% \mathrm{HA}$ (weight $\%$ ) were made in square shape $(10 \times 10 \times 10 \mathrm{~mm})$ with appropriate manufacturing parameters ensuring stability of both composite ingredients. In addition, for examination of the difference between two variants of ceramics, third type of specimens was made of PLLA and $30 \%$ of $\beta$-TCP ceramics. Technological parameters of the process are shown in Table 1. The concentration of the fillers was chosen on the basis of the deep literature research and initial empirical experiments conducted before the study.
Table 1. Technological parameters used in the preparation

of samples for microbiogical tests

\begin{tabular}{|l|l|}
\hline Laser power & $9.22 \mathrm{~W}$ \\
\hline Layer thickness & $500 \mu \mathrm{m}$ \\
\hline Scanning speed & $2.2 \mathrm{~m} / \mathrm{s}$ \\
\hline Number of scan repetitions & 5 \\
\hline
\end{tabular}

Specimens were made of polylactide and poly- $l$ -lactide (PLA and PLLA) and hydroxyapatite and tricalcium phosphate (HA and $\beta$-TCP) spherical powders in the range of particle size to $100 \mathrm{mi}-$ crons.

Three different compositions of feedstock with different polymer matrix and percentage of HA content were prepared. In Figure 5, the SLS-produced PLA/20\% HA, PLLA $/ 30 \%$ HA and PLLA $/ 30 \% \beta$-TCP composites are presented.

Differences in the topography of the samples is caused by the various concentration of HA particles. Increasing the HA content up to $30 \%$ percent increases their surface porosity. However, $\beta$-TCP powder had significantly higher level of dispersion compared to HA.

\subsection{Structure and particles distribution analysis}

According to the SEM analysis conducted on all samples series, the distribution of the particles can be described as regular and homogeneous. CT reconstructions of the fabricated samples are shown in Table 2. Comparison of the content of ceramic fillers in the material to the powders used for the process with initial concentration was done based on the binarized pictures, with particle analysis module in ImageJ software.

The concentration of the filler after fabrication of the solid samples is shown in Table 3 . (a)

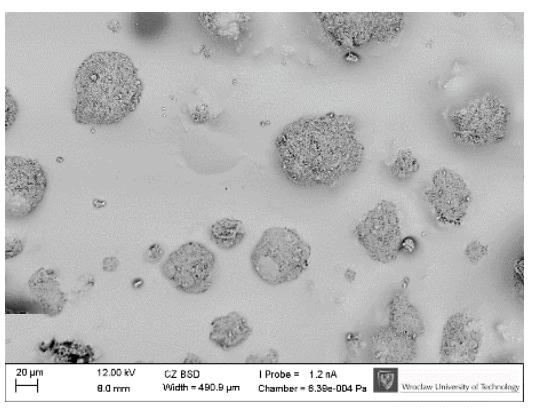

(b)

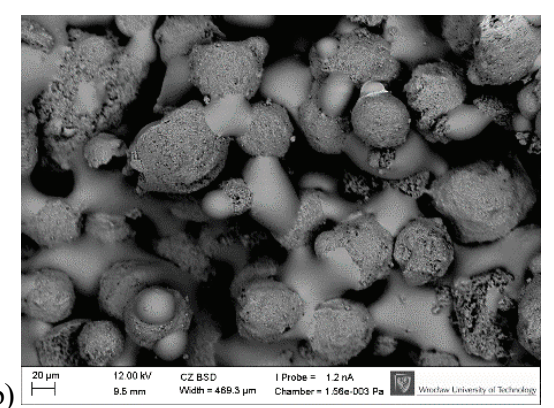

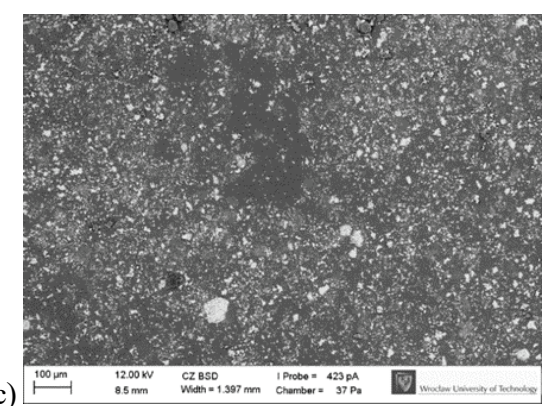

(c)

Fig. 5. Composite surfaces: (a) composite PLA with 20\% HA content,

(b) composite PLLA with 30\% HA content, (c) composite PLLA with $30 \% \beta$-TCP content 
Table 2. CT reconstruction of fabricated samples

\begin{tabular}{|l|l|l|c|}
\hline PLA $/ 20 \%$ HA & PLA $/ 30 \%$ HA & PLLA $/ 30 \%$ HA & PLLA $/ 30 \% \beta$-TCP \\
\hline & & & \\
& & & \\
\hline
\end{tabular}

Table 3. Average volume concentration of the filler in the samples

\begin{tabular}{|l|c|c|c|c|}
\hline Material & PLA $/ 20 \% \mathrm{HA}$ & PLA $/ 30 \% \mathrm{HA}$ & PLLA $/ 30 \% \mathrm{HA}$ & PLLA $/ 30 \% \beta$-TCP \\
\hline Average volume concentration & $19.24 \%$ & $32.79 \%$ & $23.48 \%$ & $19.42 \%$ \\
\hline
\end{tabular}

As observed, the average concentration of the dopants in all composites vary from the initial concentrations of the powders. This part of the study needs more complex research, because there are many factors that can influence this parameter.

\subsection{Research on selected mechanical properties}

Static compressive strength assessment - depending on the ratio of both materials (composite components) as well as in terms of their type (variety) - was a tool used for searching for properties closest to compact bone. The aim of the research was to determine the mechanical properties of composites made using L-PBF technology. Three series of samples were provided for the tests in the first stage:

1) PLA $+20 \%$ HA composite,

2) PLA $+30 \%$ HA composite,

3) $\mathrm{PLA}+50 \%$ HA composite, and 2 further series of samples in the second stage:

4) PLLA $+30 \%$ HA composite,

5) PLLA composite $+30 \% \beta$-TCP.

The first stage of fabrication was to select the concentration corresponding to the most expected properties. After the samples were produced in the first stage, they were subjected to preliminary tests to determine which material concentration was going to be used in the case of using other components of the composite. The optimization carried out was to reduce the number of samples when medical materials were used, due to their high price and limited availability.

The results obtained in the first series showed that the composite with $50 \%$ concentration of HA is not suitable for further tests, due to its excessive brittleness.

Composites for testing with HA content were produced in concentrations of 20 and $30 \%$. The conducted tests showed that the composite with a $30 \%$ concentration of ceramics exhibited the best strength properties, therefore composites with PLLA and $\beta$-TCP were chosen for further testing.

Samples prepared with the use of processing parameters that did not affect the structural changes of the composite components were ground in order to even out the surface and ensure parallelism. Strength tests, including a compression test, were carried out on the INSTRON 3384 testing machine. The purpose of the mechanical compression test was to determine the characteristics (stress-strain) $\sigma=f(\varepsilon)$, on the basis of which the values of stresses causing material damage. A measuring head for tensile and compression tests was used $-10 \mathrm{kN}(2.250 \mathrm{lb})$ with an accuracy class of $0.5 \%$ with disk holders for the compression test.

During the tests, the measurement was performed at a beam displacement speed of $0.5 \mathrm{~mm} / \mathrm{min}$. Before each measurement, an automatic calibration of the measuring head was performed. Under the influence of the compressive force, the material was compressed and no cracks appeared in it. The criterion of the end of the test was the achievement of $60 \%$ of the sample displacement value. Due to the dimensions of the samples defined in the testing machine software, the stress values were easily obtained and plotted on the sample compression charts.

\subsection{In vitro tests}

A human osteoblast U2 OS line from the $\mathrm{ATCC}^{\circledR}$ HTB96 ${ }^{\mathrm{TM}}$ collection (American Cell Culture Collection) was used in the in vitro study. This line belongs to the group of continuous cell lines, it is isolated from spongy bone and is most often used in the research of biomaterials that are to be used as bone im- 
plants. Osteoblasts, as osteogenic cells, are characterized by the ability to mineralize and synthesize elements of the intercellular matrix.

\subsubsection{Quantitative cultures}

The development of cell culture was monitored by observation using light microscopy methods, observation of cell growth, on the tested material, was carried out using scanning microscopy methods, while the number of cells was calculated based on the NRU test according to PN-EN ISO 10993-5, using a modified test NR and the Moxy $Z$ cell reader.

In the initial stages of the study, the U2 OS osteoblast was cultured in accordance to ATCC guidelines in the DMDE/HAM's F12 MIX cell culture medium enriched with $10 \%$ fetal serum. The process was carried out in the atmosphere with the addition of $5 \% \mathrm{CO}_{2}$, at full humidity at $37{ }^{\circ} \mathrm{C}$. The condition of the culture was monitored using inverted microscope (Fig. 6).

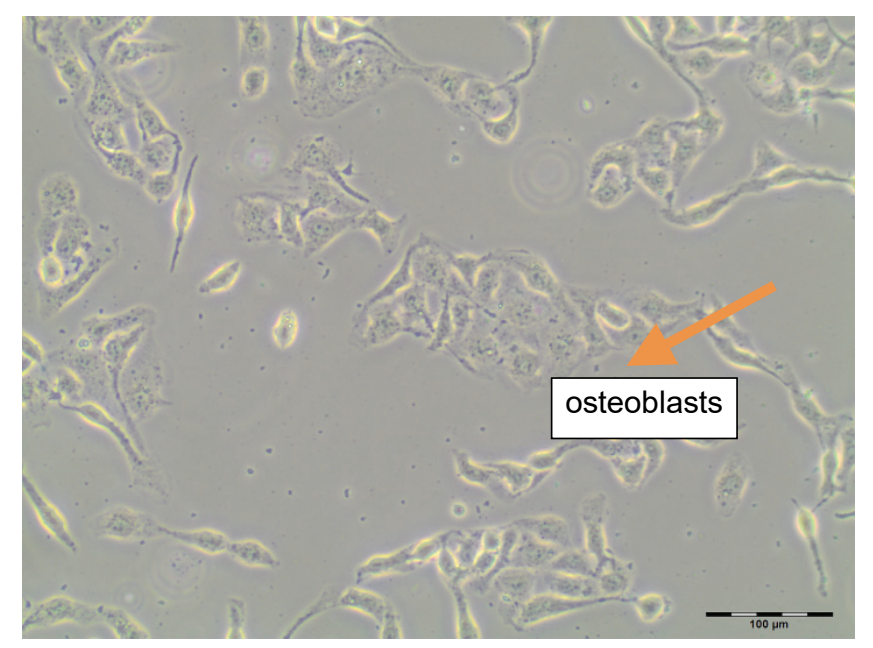

Fig. 6. Osteoblast cells after 24-hour cultivation

Once monolayer growth was found, the culture was detached with trypsin and the number of cells obtained was counted in a Bruckner chamber. In the next step, the osteoblast density was adjusted to the value of $1.5 \times 10^{5}$ cells $/ \mathrm{mL}$. The culture prepared in this way was used in subsequent stages of the research.

The prepared materials in composition of PLA and $20 \%$ HA, PLLA and 30\% HA and PLLA and $30 \% \beta$-TCP were sterilized at the temperature of $120^{\circ} \mathrm{C}$. The samples were then placed in $1 \mathrm{ml}$ of sterile cell culture medium containing fetal serum and left for 24 hours under controlled conditions $\left(37^{\circ} \mathrm{C} / 5 \% \mathrm{CO}_{2} /\right.$ $100 \%$ humidity). The samples were removed from the medium after the incubation time had elapsed, and the solution was applied to a previously prepared 24-hour osteoblast culture in a 96-well cell culture plate. The plate was incubated under the controlled conditions previously described: $37{ }^{\circ} \mathrm{C} / 5 \% \mathrm{CO}_{2} / 100 \%$ humidity for 24 or 48 hours. After the incubation time had elapsed, the medium was removed and the plates were rinsed with saline. Then, each well was placed with an NR solution $(100 \mu \mathrm{l} /$ well $)$ using a dropper and incubation was started for $3 \mathrm{~h}$ under controlled conditions $\left(37^{\circ} \mathrm{C} / 5 \% \mathrm{CO}_{2} / 100 \%\right.$ humidity). After the incubation time had elapsed, the plates were washed with PBS buffer and allowed to dry at room temperature. Then, $100 \mu 1$ of the red extraction solution was introduced into the wells, and the plate was shaken for 25 minutes in the dark and analyzed using the UVM-340 spectometer, which consisted in measuring the optical density at a wavelength of $540 \mathrm{~nm}$.

\subsubsection{Cultivation of U2 OS osteoblasts in the presence of bioresorbable composites}

Osteoblasts were grown according to the procedure described in the previous section. Then, a $1 \mathrm{ml}$ suspension in an amount of $1.5 \times 10^{5}$ cfu was introduced into the wells of a 24-well plate, in which the samples of bioresorbable composites of various compositions were previously placed. Cells were incubated in the presence of samples for 7, 14 and 21 days. The medium was changed every 48 hours or more frequently if its colour changed from red to yellow, which indicated that the nutrients contained in it were consumed. All samples were statically populated.

To verify the growth rate and characteristics of cell adhesion to the surface of the tested materials, a microscopic analysis was performed using a scanning electron microscope (SEM). A special preparation scheme was used to prepare samples with biological material for microscopic examination. The samples incubated at the three control times were carefully removed from the wells of a 24 -well plate, then immersed in $2.5 \%$ glutardehyde and incubated in the dark for $4 \mathrm{~h}$ at $4{ }^{\circ} \mathrm{C}$. After the incubation time had elapsed, the samples were rinsed $(3 \times 4 \mathrm{~min})$ with distilled water. After washing, the samples were subjected to the dehydration process in the ethanol series with the following concentrations: $25,50,70,80,90$, and $100 \%$, by incubating each sample at individual concentrations for 10 minutes. The samples were then dried at room temperature. In order to prepare the samples for observation with the use of scanning electron microscopy methods, the material was subjected to plasma sputtering of the $\mathrm{Au} / \mathrm{Pd}$ conductive material (60:40) using the QUORUM Q150R ES device and subjected to microscopic analysis [22]. 


\section{Results}

\subsection{Mechanical properties}

Based on the graphs, the maximum values of stresses and loads at the point of fracture were read, and then, used to determine the equivalent Young's Modulus for the tested material. Taking the porosity occurring in the samples in the range from 11 to $13 \%$ [28] into account, the strength properties can be understated. That is the reason of determination of the equivalents. In order to compare the quality of the material from which the samples were prepared, the values of the equivalent compressive stress and the equivalent Young's Modulus were adopted. The averaged values of the equivalent compressive stress, the equivalent Young's Modulus for a material with 20\% and 30\% HA content are summarized in Table 4.

Table 4. Equivalent compressive stress, the equivalent Young's Modulus and the maximum load for a material with $20 \%$ and $30 \% \mathrm{HA}$

\begin{tabular}{|c|c|c|}
\hline Material & $\begin{array}{c}\text { Equivalent } \\
\text { compressive stress [MPa] }\end{array}$ & $\begin{array}{c}\text { Equivalent } \\
\text { Young's Modulus [MPa] }\end{array}$ \\
\hline $20 \%$ HA & $22.42 \pm 7.28$ & $29.06 \pm 6.11$ \\
\hline $30 \%$ HA & $56.12 \pm 2.47$ & $70.29 \pm 1.51$ \\
\hline
\end{tabular}

Samples produced by the L-PBF method with the same parameters and sintering algorithms differ in the ability to transfer stresses depending on the applied values of the ceramic concentration. There is an over two-fold increase in both the value of the compressive stress and the equivalent Young's Modulus for the material with a $10 \%$ increase in the ceramic content in the composite composition.

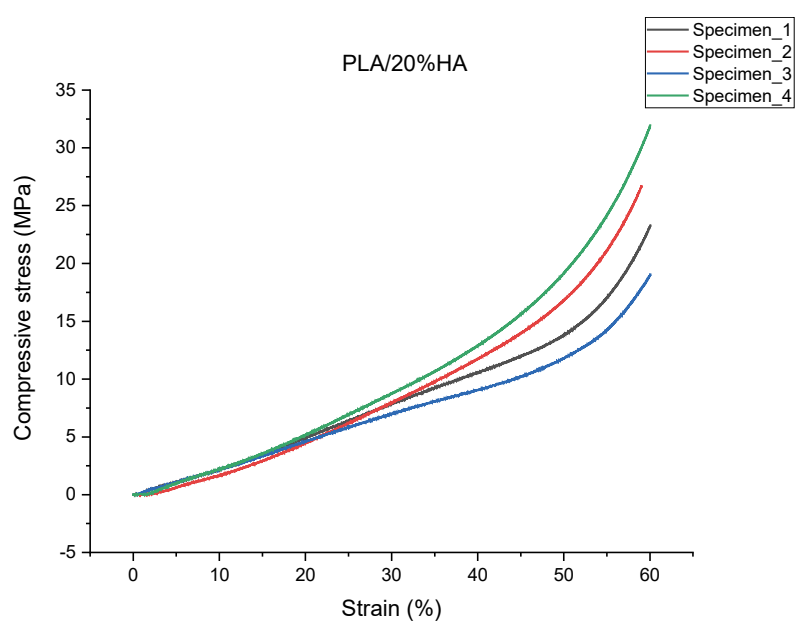

Fig. 7. Relationship between compressive stress and strain for material based on PLA matrix with 20\% HA dopant

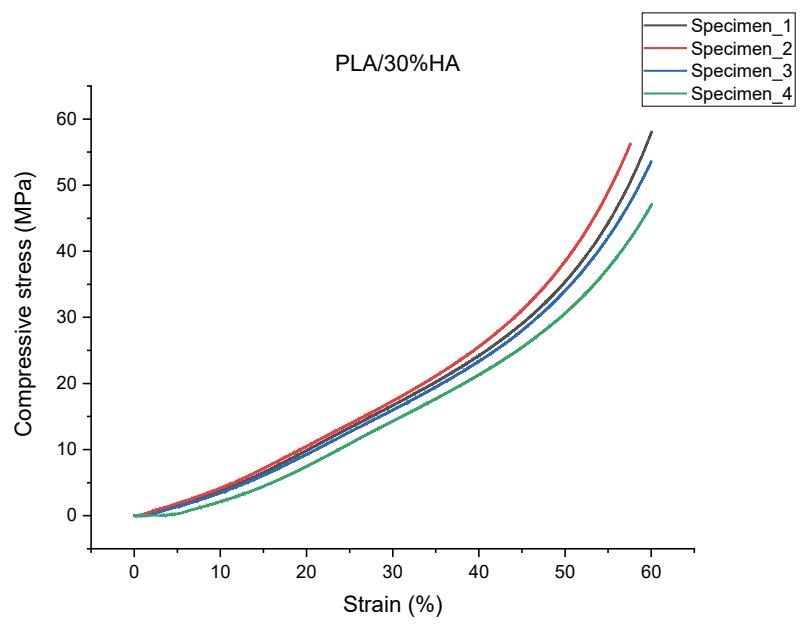

Fig. 8. Relationship between compressive stress and strain for material based on PLA matrix with $30 \%$ HA dopant

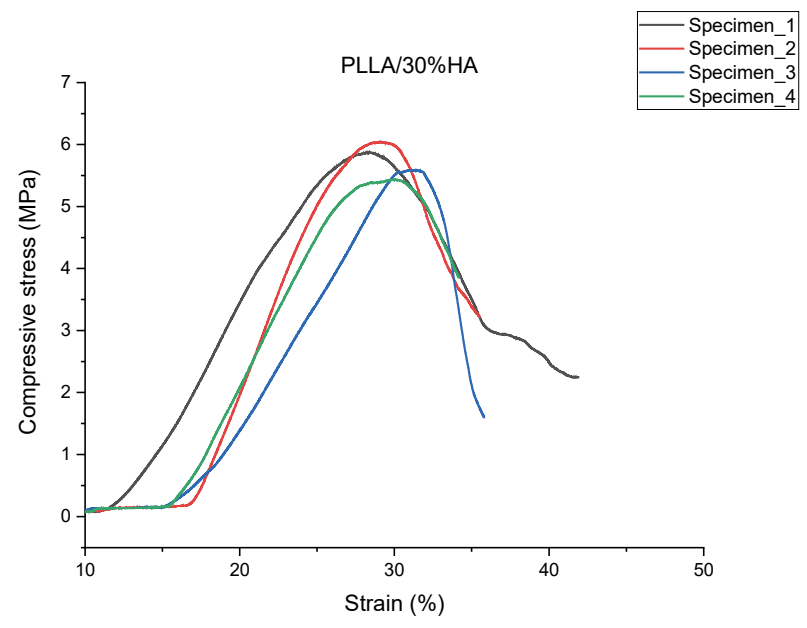

Fig. 9. Relationship between compressive stress and strain for material based on PLLA matrix with 30\% HA dopant

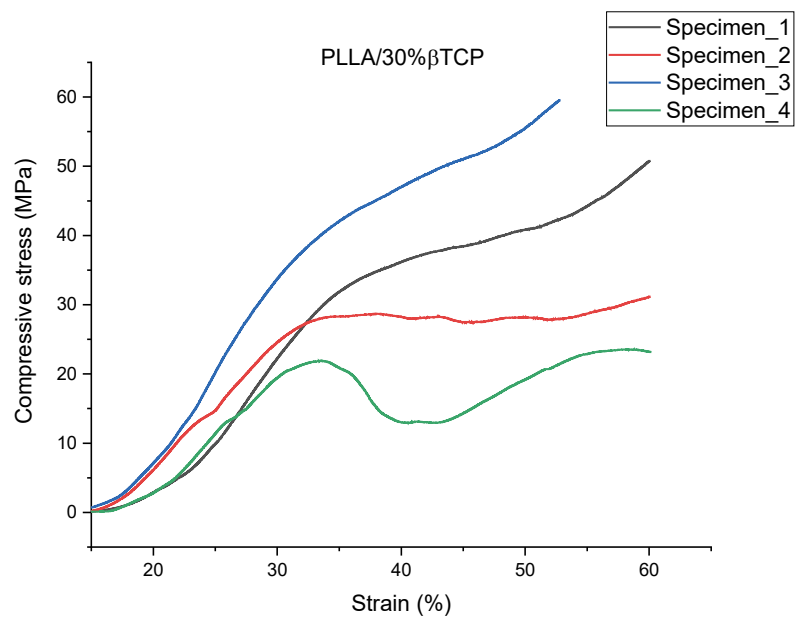

Fig. 10. Relationship between compressive stress and strain for a PLLA matrix material with $30 \% \beta$-TCP dopant

In the next step, composite samples were produced using poly-1-lactide and hydroxyapatite and Whitoclite ceramics at a concentration of $30 \%$. The pro- 
duced material was tested in accordance with a previously developed procedure.

As in the case of the previously tested materials, graphs were obtained showing the relationship between compressive stress and strain (Figs. 7-10). The values of stresses and the equivalent Young's Modulus were also determined, which are summarized in Table 5.

Table 5. The mean values of the compressive stress and the equivalent Young's Modulus

\begin{tabular}{|l|c|c|}
\hline \multicolumn{1}{|c|}{ Material } & $\begin{array}{c}\text { Equivalent } \\
\text { compressive stress } \\
{[\mathrm{MPa}]}\end{array}$ & $\begin{array}{c}\text { Equivalent } \\
\text { Young's Modulus } \\
{[\mathrm{MPa}]}\end{array}$ \\
\hline PLLA+30\% HA & $5.32 \pm 0.95$ & $49.34 \pm 11.20$ \\
\hline PLLA+30\% $\beta$-TCP & $31.93 \pm 8.96$ & $236.63 \pm 17.08$ \\
\hline
\end{tabular}

Graphs of the relationship between the compressive stress and the strain obtained for the samples made of PLLA and 30\% HA dopant show that this material in its strength characteristics corresponds more to a ceramic material than a polymer one. The compression test runs clearly show the brittle fracture of the material, which, after reaching the maximum compressive stress, does not strengthen as does plastic. The material made of PLLA with a $30 \%$ admixture of $\beta$-TCP behaves in a completely opposite way - its strength characteristics correspond to the course of the stress curve for polymers, where a relatively small area of elasticity changes smoothly into a much larger area of plasticity, in which the material does not break, but only gradually strengthens. The composites with $\beta$ TCP is only sintered with PLLA matrix, thus the influence of $\beta$-TCP on mechanical properties cannot be compared to influence of HA.

By analysing the results of the compression tests for each series of samples different in terms of chemical composition, it can be concluded that the PLAbased material with $30 \%$ HA doping is characterized by the highest strength combined with a relatively low stiffness, which is illustrated by the obtained value of the equivalent Young's modulus. Due to its strength and resilient nature, such material could be used as a bone restoration subjected to continuous and cyclical loads, such as elements of skeletal bones. On the other hand, the material based on PLLA with an admixture of $\beta$-TCP is characterized by medium strength, but definitely stands out in terms of stiffness, which is close to the parameters observed in natural tissues this type of material could be used in places that do not carry greater loads, but require stabilization such as, e.g., craniofacial bones. The conducted research proves that the properties of the produced bioresorb- able composites can be controlled by the components used, their form and concentration.

\subsection{Confirmation of $\mathrm{U} 2 \mathrm{OS}$ (ATCC $^{\circledR}$ HTB96 $^{\mathrm{TM}}$ ) osteoblasts strain to form biofilm on the biomaterials. The results of the cytotoxicity study}

The tests were performed in triplicate in order to eliminate errors caused by the influence of the environment. The results are presented in Table 6 .

Table 6. Number of cells after incubation after 24 and $48 \mathrm{~h}[\%]$

\begin{tabular}{|c|c|c|c|c|}
\cline { 2 - 5 } \multicolumn{1}{c|}{} & $\begin{array}{c}\text { Cell control } \\
{[\%]}\end{array}$ & $\begin{array}{c}\text { PLA/20\% } \\
\text { HA [\%] }\end{array}$ & $\begin{array}{c}\text { PLLA/30\% } \\
\text { HA [\%] }\end{array}$ & $\begin{array}{c}\text { PLLA/30\% } \\
\beta \text {-TCP [\%] }\end{array}$ \\
\hline $24 \mathrm{~h}$ & 100 & 83.2 & 94.3 & 91.1 \\
\hline $48 \mathrm{~h}$ & 100 & 81.4 & 74.6 & 80.6 \\
\hline
\end{tabular}

In both, the first and the second control time, the cells had a lower abundance than the control sample. The best results after 24 hours of incubation were characterized by PLLA matrix composites with $30 \%$ HA addition, while the lowest result was achieved by PLA matrix material with $20 \% \mathrm{HA}$ addition. It is worth noting, however, that the levels of all results are referred to as "low cytotoxicity, high survival". About $10 \%$ difference in the results between PLLA and PLA composites (to the disadvantage of the latter polymer) confirms the hypothesis about better biological properties of PLLA.

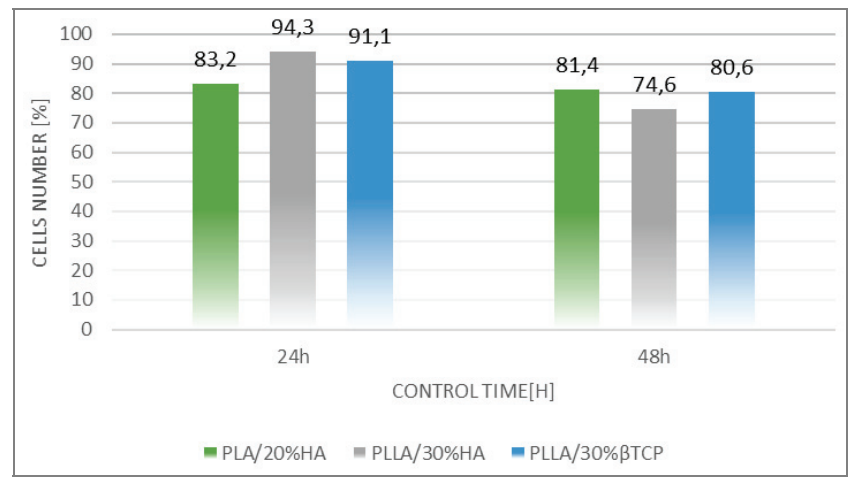

Fig. 11. Cytotoxicity test results after 24 and 48 hours

After $48 \mathrm{~h}$ incubation, it was noticed that cell survival decreased for each batch of samples. The largest decrease, as much as $20 \%$, was recorded for the material which, in the case of the $24 \mathrm{~h}$ control time, was characterized by the best survival rate - PLLA / 30\% HA, while the PLA / 20\% HA composite turned out to be the most stable material, because the decrease in 
survival was only about $2 \%$. However, the tested materials can still be characterized as safe, since the lowest survival value after 24 hours indicates "moderate cytotoxicity, slight reduction in viability", while the other two results are referred to as "low cytotoxicity, high survival".

\subsection{Cultivation of U2 OS osteoblasts in the presence of bioresorbable composites}

Cell counts were calculated based on the NR test. The colonization process of bioresorbable composites was carried out according to the method described above. After the incubation time had elapsed, the samples were removed from the growth medium, rinsed with PBS buffer, and covered with $1 \mathrm{ml}$ of NR solution. Then, the procedure preceding the cytotoxicity assessment was performed. The control of the research sample consisted of samples placed in a culture medium devoid of osteoblasts. The quantitative results are presented in Table 7.

Table 7. Cell counts after 7, 14 and 21 days of incubation versus control

\begin{tabular}{|c|c|c|c|c|}
\cline { 2 - 5 } \multicolumn{1}{c|}{} & Control & $\begin{array}{c}\text { PLA/20\% } \\
\text { HA }\end{array}$ & $\begin{array}{c}\text { PLLA/30\% } \\
\text { HA }\end{array}$ & $\begin{array}{c}\text { PLLA/30\% } \\
\beta \text {-TCP }\end{array}$ \\
\hline 7 day & 100 & 118.10 & 93.69 & 108.51 \\
\hline 14 day & 100 & 130.97 & 110.87 & 117.07 \\
\hline 21 day & 100 & 143.51 & 116.44 & 152.87 \\
\hline
\end{tabular}

The values shown are the average of the results of three cell count tests after 7, 14 and 21 days of incubation versus a control sample. The presence of osteoblasts can be observed on all the materials tested. With the passage of time, a clear quantitative increase in the number of cell colonies is visible, therefore, the extension of the time increases the number of cells on

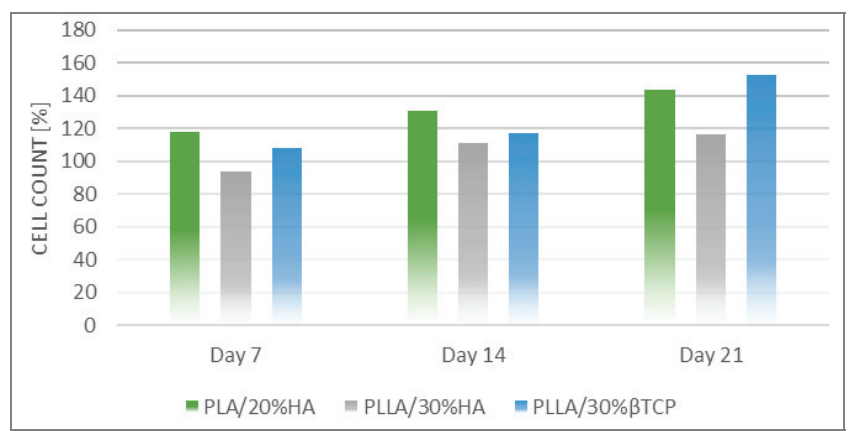

Fig. 12. Cell counts after specified control times the surface of the tested materials. Particular types of materials differ in their ability to overgrow with boneforming cells. As shown in Fig. 12, the most stable material is PLA composite with $20 \%$ HA dopant. Cell growth in this case is stable and linear at each of the control times.

The lowest number of osteogenic cells was observed in the PLLA composite with $30 \%$ admixture of HA, while the PLLA composite with $30 \%$ of $\beta$-TCP showed the highest growth of osteoblast colonies among all the tested materials. After 21 days there was over $150 \%$ cell growth. It is a clear confirmation of better biological parameters of $\beta$-TCP in relation to pure hydroxyapatite.

\section{Discussion}

All the factors: dynamic development of biomaterial engineering, increasing need for new materials, development of methods of their processing and new, innovative manufacturing technologies of bone supplements, forces research teams to constantly seek solutions, which stimulates interdisciplinary works. Relatively new, additive manufacturing methods, broaden the spectrum of biomaterials manufacturing methods, which translates directly into the development of modern surgery. However, as shown in a numerous papers, there are still number of complications on the way to successful treatment with customized, bioresorbable bone implant. One of the most frequently mentioned problems is the problem with osseointegration [9], [10], [23]. For the reinforcement of this natural and desired process, different bioresorbable materials were used as coatings. In [20], resorbable calcium phosphate coatings were introduced on the titanium implants. It was clearly proved that titanium implant with ceramic coating, integrated much better with the bone. Authors of [10] recognizes different methods of coating materials with osteoconductive calcium phosphate on dental implants. [9] brings up the topic of microrough RBM surfaces due to incorporation of $\mathrm{CaP}$ particles onto the titanium surfaces. Therefore, results presented in this paper, gives the overview on the bioresorbable materials processed with the method, that can change their structure. Moreover, researchers in [26] proved osteoblast proliferation increased on all nanophase ceramics tested in their study, which means alumina, titania and hydroxyapatite are also good materials in terms of osseointegration precursors. Additive manufacturing methods are opening new possibilities, but, at the same time, 
are also a scientific challenge on their own. The complexity of the process, and sensibility for many different factors, makes them an important part of every study. One of the important parameters is laser power, which determines the final properties of processed materials. Such sensitive materials as polymers, needs deep research of how the processing influences the product. Authors of [29] highlight that the laser power in their study played an important role. It influenced the sintering morphology and binding strength of the composite microspheres. In the study, it was also pointed out that the chemical component of PLA/ nano-HAP composite microspheres was not affected by their exposure to laser energy. Additive manufacturing methods also enables new materials to process. The materials, which were known, but difficult to formation. One of the newest metal biomaterials - Zn was reinforced with reduced graphene oxide (RGO), for improving mechanical properties in perspective to use $\mathrm{Zn}$ in bone surgery [30].

Idea of combining bioresorbable materials such as polymers and ceramics for manufacturing customizable implants, which due to resorption of the polymer matrix and release of bioceramics, will stimulate osseointegration is developed in recent years [6], [15], [21], [24]. All the studies point out to the huge potential and excellent biocompatibility properties of the tested materials. However, there are also conclusions that HA effect on bone metabolism after surgery in first few months may be favorable, but in long-term it may cause complications [25]. Authors of research [13] concluded that surface modification with $\mathrm{CO}_{2}$ laser beam lowers the strength properties of the polymer, but, as proved in this paper, addition of HA powders as well as the form of the processed polymer, can significantly lower the maximum power of the laser beam needed to process the polymer material. This is definitely an interesting field for further analysis. Conducted experiments and obtained results can confirm the aim presented in the introduction, that human bone cells are able to form colonies on PLA/HA composites made with L-PBF laser technology, of various chemical composition within individual samples. Determined mechanical properties are also highlighting the strengths and weaknesses of composite materials fabricated with L-PBF method. Research performed and presented in this article is, therefore, a promising next point to conduct experiments, where various compositions of bioresorbable composites would be implemented in aim of reduction of complications caused by sensitive to the number of factors, natural process of osseointegration.

\section{References}

[1] Amado A., Schmid M., Levy G., Wegener K., Advances in SLS powder characterization, 22nd Annual International Solid Freeform Fabrication Symposium - An Additive Manufacturing Conference, SFF 2011, 2011, 438-452.

[2] Bayraktar H.H., Morgan E.F., Niebur G.L., Morris G.E., WONG E.K., KEAVENY T.M., Comparison of the elastic and yield properties of human femoral trabecular and cortical bone tissue, J. Biomech., 2004, 37 (1), 27-35.

[3] Berretta S., Ghita O., Evans K.E., Anderson A., Newman C., Size, shape and flow of powders for use in Selective Laser Sintering (SLS), High Value Manufacturing: Advanced Research in Virtual and Rapid Prototyping, Proceedings of the 6th International Conference on Advanced Research and Rapid Prototyping, VR@P 2013, 2014, 49-54.

[4] Brown P.W., Constantz B., Hydroxyapatite and Related Materials, Taylor \& Francis Group, Boca Raton: CRC Press, 1994.

[5] BRUNSKi J.B., 36. Influence of Biomechanical Factors at the Bone-Biomaterial Interface, Bone-Bio Material Interface, University of Toronto Press, 2016.

[6] Dias G.J., Mahoney P., Swain M., Kelly R.J., Smith R.A., Ali M.A., Keratin-hydroxyapatite composites: Biocompatibility, osseointegration, and physical properties in an ovine model, J. Biomed. Mater. Res., 2010, 95A (4), 1084-1095.

[7] DoROZHKIN S.V., Calcium orthophosphates: occurrence, properties, biomineralization, pathological calcification and biomimetic applications, Biomatter, 2011, 1 (2), 121-164.

[8] Duda A., PenczeK S., Polilaktyd [poli(kwas mlekowy)]: synteza, wtaściwości i zastosowania, Polimery, 2003, T. 48, nr 116-127.

[9] Galli S., Jimbo R., Tovar N., Yoo D.Y., Anchieta R.B., YAMAGUChI S., CoElho P.G., The effect of osteotomy dimension on osseointegration to resorbable media-treated implants: A study in the sheep, J. Biomater. Appl., 2015, 29 (8), 1068-1074.

[10] Le GuÉhennec L., Soueidan A., Layrolle P., AmouriQ Y., Surface treatments of titanium dental implants for rapid osseointegration, Dent. Mater., 2007, 23 (7), 844-854.

[11] Hayashi H., Uchida A., Hamada H., Yoshikawa H., ShINTO Y., ONO K., Alumina ceramic prostheses for bone tumor surgery, Arch. Orthop. Trauma Surg., 1992, 112 (1), 1-4.

[12] Hoeges S., Lindner M., Fischer H., Meiners W., WiSSENBACH K., Manufacturing of bone substitute implants using selective laser melting, IFMBE Proceedings, 2008, 2230-2234.

[13] Kobielarz M., Gazińska M., Tomanik M., StęPak B., Szustakiewicz K., Filipiak J., Antończak A., Pezowicz C., Physicochemical and mechanical properties of $\mathrm{CO}_{2}$ lasermodified biodegradable polymers for medical applications, Polym. Degrad. Stabil., 2019, 165182-195.

[14] Mao Y., Dong Y., Lin P., Chu C., Sheng X., Guo C., Preparation of poly(l-lactic acid) microspheres by droplet-freezing process, Mater. Sci. Eng. C, 2011, 31 (1), 9-13.

[15] McManus A.J., Doremus R.H., Siegel R.W., Bizios R., Evaluation of cytocompatibility and bending modulus of nanoceramic/polymer composites, J. Biomed. Mater. Res., 2005, 72A (1), 98-106.

[16] Pielichowska K., Blazewicz S., Bioactive Polymer/ Hydroxyapatite (Nano)composites for Bone Tissue Regeneration, [in:] A. Abe, K. Dusek, S. Kobayashi (Eds.), Biopolymers: 
Lignin, Proteins, Bioactive Nanocomposites, Springer, Berlin, Heidelberg 2010, 97-207.

[17] Russias J., Saiz E., Nalla R.K., Tomsia A.P., Microspheres as building blocks for hydroxyapatite/polylactide biodegradable composites, J. Mater. Sci., 2006, 5127-5133.

[18] SAUTIER J., Nefussi J., ForeSt N., Ultrastructural Study of Bone Formation on Synthetic Hydroxyapatite in Osteoblast Cultures, Cell. Mater., 1991, 1 (3), 209-2017.

[19] Schmid M., Amado A., Wegener K., Polymer powders for selective laser sintering (SLS), AIP Conference Proceedings, 2015, 160009.

[20] Schwarz M.L.R., Kowarsch M., Rose S., Becker K., LenZ T., JANI L., Effect of surface roughness, porosity, and a resorbable calcium phosphate coating on osseointegration of titanium in a minipig model, J. Biomed. Mater. Res. A, 2009, 89A (3), 667-678.

[21] Shin D.Y., KANG M.H., KANG I.G., KIM H.E., JeONG S.H., In vitro and in vivo evaluation of polylactic acid-based composite with tricalcium phosphate microsphere for enhanced biodegradability and osseointegration, J. Biomater. Appl., 2018, 32 (10), 1360-1370.

[22] Szymczyk P., Junka A., ZióŁkowski G., Smutnicka D., Bartoszewicz M., Chlebus E., The ability of $S$. aureus to form biofilm on the Ti-6Al-7Nb scaffolds produced by Selective Laser Melting and subjected to the different types of surface modifications, Acta Bioeng. Biomech., 2013, 15 (1), 69-76.

[23] TAYLOR T.D., Prosthodontic problems and limitations associated with osseointegration, J. Prosthet. Dent., 1998, 79 (1), $74-78$.
[24] Tcacencu I., Rodrigues N., Alharbi N., Benning M., Toumpaniari S., Mancuso E., Marshall M., Bretcanu O., Birch M., McCaskie A., Dalgarno K., Osseointegration of porous apatite-wollastonite and poly(lactic acid) composite structures created using $3 D$ printing techniques, Mater. Sci. Eng. C, 2018, 901-907.

[25] Urbański W., KrawczyK A., Dragan S.Ł., Kule M., DRAGAN S.F., Influence of cementless cup surface on stability and bone fixation 2 years after total hip arthroplasty, Acta Bioeng. Bimech., 2012, 14 (2), 27-35.

[26] Webster T.J., Ergun C., Doremus R.H., Siegel R.W., Bizios R., Enhanced functions of osteoblasts on nanophase ceramics, Biomaterials, 2000, 21 (17), 1803-1810.

[27] Wenisch S., Stahl J.-P.P., Horas U., Heiss C., Kilian O., TRINKAUS K., HiLD A., SCHNETTLER R., In vivo mechanisms of hydroxyapatite ceramic degradation by osteoclasts: Fine structural microscopy, J. Biomed. Mater. Res. A, 2003, (3), 713-718.

[28] WoźNA A.E., JunKa A.F., SZYMCZYK P.E., The influence of different composite mixtures (PLA/HA) manufactured with additive laser technology on the ability of $S$. aureus and $P$. aeruginosa to form biofilms, Acta Bioeng. Biomech., 2018, 20 (3), 101-106.

[29] Yan D., Zeng B., Han Y., Dai H., Liu J., Sun Y., Li F., Preparation and laser powder bed fusion of composite microspheres consisting of poly(lactic acid) and nanohydroxyapatite, Addit. Manuf., 2020, 34101305.

[30] Yang Y., Cheng Y., Peng S., Xu L., He C., Qi F., Zhao M., SHUAI C., Microstructure evolution and texture tailoring of reduced graphene oxide reinforced $Z n$ scaffold, Bioact. Mater., 2021, 6 (5), 1230-1241. 